\title{
O COOPERATIVISMO HÍBRIDO E SUAS FORMAS DE ATUAÇÃO NO PARANÁ
}

\section{LA COOPERATIVA HÍBRIDA Y SUS FORMAS DE ACCIÓN EN PARANÁ}

\section{THE HYBRID COOPERATIVE AND ITS FORMAS OF ACTION IN PARANÁ}

\author{
Elpídio Serra \\ Universidade Estadual de Maringá - Programa de Pós-Graduação em Geografia \\ elpidio_serra@hotmail.com
}

\begin{abstract}
Resumo
As cooperativas que atuam no setor agrícola do Paraná, em sua maior parte, surgiram como empresas mercantis vinculadas ao recebimento e ao repasse para o mercado de matérias primas entregues pelos agricultores associados, passando em seguida por intenso processo evolutivo para se transformarem em grandes empresas comerciais e industrias integradas ao agronegócio. $\mathrm{Na}$ nova fase assumem um comportamento híbrido e contraditório ao operar, ao mesmo tempo e com a mesma estrutura, com associados livres, associados integrados e terceiros (agricultores não associados). $\mathrm{O}$ presente trabalho aborda tal evolução e tal comportamento, tomando como referências as cooperativas COCAMAR, sediada em Maringá, região Norte e C. VALE, sediada em Palotina, região Oeste do Paraná, destacando que pela nova forma de agir as empresas se distanciam de suas bases sociais e dos princípios ideológicos do cooperativismo como sistema universal, baseado em sociedade de pessoas e não de capitais.
\end{abstract}

Palavras-chave: cooperativismo; agronegócio; Paraná; empresas híbridas; industrialização.

\section{Resumen}

Las cooperativas que operan en el sector agrícola de Paraná, en su mayor parte han surgido empresas como del mercado de trabajo en la recepción y repase para el mercado de materias primas proporcionadas por los agricultores implicados, que pasa por un intenso proceso evolutivo y se convirtió en un gran empresas comerciales y la agroindustria integrada de las industrias. En la nueva fase son un híbrido y contradictorio comportamiento cuando se opera al mismo tiempo y con la misma estructura, con los miembros libres, integrados y asociados y terceros (los agricultores no asociados). El presente artigo responde a esos acontecimientos y ese tipo de comportamiento, teniendo como referencias COCAMAR las cooperativas, con sede en Maringa, en el norte y C. Vale, con sede en Palotina, la región occidental de Paraná, destacando que la nueva forma de actuar las empresas están distanciam de sus bases sociales y los principios ideológicos de las cooperativas como sistema universal, sobre la base de la sociedad de las personas y no de capital.

Palabras-clave: Cooperativa; agronegócios; Paraná; híbrido empresas; industrialización. 


\begin{abstract}
The cooperatives operating in the agricultural sector of Paraná, for the most part have emerged as market companies working in receiving and repassing to the market for raw materials supplied by the farmers involved, then passed by an intense evolutionary process and became a big commercial enterprises and the integrated agribusiness industries. In the new phase are a hybrid and contradictory behavior when operating at the same time and with the same structure, with free members, associated and others producers (who don't fit into any of these categories). This article treats of developments and such behavior, taking as references COCAMAR, based in Maringá, northern of the Paraná, and C. VALE, based in Palotina, the western region of Paraná, stressing that the new form of acting companies are so far table of associations and their own ideological principles of cooperatives as universal system, based on society of people and not capital.
\end{abstract}

Keywords: co-operativism; agribusiness; Paraná; hybrid companies; industrialization.

\title{
INTRODUÇÃO
}

O cooperativismo, enquanto sistema universal romanticamente baseado na filosofia do "um por todos, todos por um", da "união faz a força" e de uma série de outros slogans que incorporam a importância da união de pessoas e respectivas funções como caminho para a sua inserção nas relações capitalistas de produção e de trabalho, vem sofrendo nos últimos tempos um processo de transformação muito forte, a ponto de não se ter em determinadas situações como separar uma cooperativa de uma empresa privada comum, dados os níveis de aproximação entre os segmentos privado e coletivo. Diante da situação criada, o presente trabalho se propõe, tomando como referência de análise a COCAMAR - Cooperativa Agroindustrial de Maringá, na região Norte e a C. VALE - Cooperativa Agroindustrial, sediada no município de Palotina, região Oeste do Paraná, a analisar os motivos que vão justificar o nivelamento das cooperativas com as empresas ditas comuns, bem como as vantagens e as desvantagens que em função disso transferem aos associados, antes "com certeza" e atualmente "talvez" os verdadeiros donos das cooperativas. Como procedimento metodológico o trabalho procura, num primeiro momento, resgatar os princípios e valores que nortearam a formação da proposta cooperativista no século XVIII, sustentada nas utopias de Owen, Blanc, King, Fourier e de outros pensadores da época, que se preocupavam com a exclusão social e suas consequências mais evidentes (fome, miséria, desemprego...) que "poderiam" ser produzidas pelo capitalismo ainda nascente; a sua implantação no século XIX quando a Revolução Industrial veio provar que os pensadores estavam certos; a sua prática no século XX, já inserida no capitalismo estruturado e já incorporando alguma prática 
empresarial estranha ao seu berço ideológico e filosófico; num segundo momento, procura analisar a prática cooperativista atual e estabelecer algum tipo de comparação entre a teoria e a prática cooperativista, usando como referencial as duas cooperativas paranaenses.

As cooperativas sediadas em Maringá e em Palotina, com áreas de atuação, respectivamente, em municípios da região Norte e em municípios da região Oeste do Paraná, são utilizadas como referenciais, dadas as muitas coincidências que apresentam entre si. As duas, embora geograficamente distantes uma da outra, foram fundadas no mesmo ano de 1963 como empresas mercantis; tiveram, na fundação, a interferência governamental, o que significa que não surgiram, propriamente das bases como estabelece a proposta do sistema cooperativista; destinaram-se, de início, a atender produtores rurais em crise; elas próprias enfrentaram crises; ampliaram suas áreas de atuação e se industrializaram; trocaram de nome nos momentos que vão definir novas características de sua atuação empresarial, enfim tiveram praticamente a mesma trajetória de crescimento e hoje se constituem nas maiores cooperativas do Paraná em termos de capacidade de transformação da produção dos associados. Em síntese, a COCAMAR e a C. VALE passaram por todas as fases recentes da evolução do cooperativismo agrário brasileiro, operando, de início, em função de recebimento e comercialização de matérias-primas entregues pelos agricultores associados e, em seguida, como centros de transformação e industrialização dessas mesmas matériasprimas, repassando ao mercado consumidor, direta e indiretamente, não mais matériasprimas, mas produtos elaborados. Agregando valores a partir da transformação de matérias-primas em produtos industrializados, conseguiram se estruturar como modernas empresas capitalistas, em condições de atuar em nível de igualdade com o grande capital industrial, no mesmo segmento econômico. Além da agregação de valores, contribuiu para essa transformação uma política de benefícios físcais carreada pelo Estado para as cooperativas, principalmente durante os anos 1970 e parte dos anos 1980, através da qual a COCAMAR e a C. VALE foram altamente beneficiadas. O Estado, ao carrear créditos subsidiados para as cooperativas, contribuiu para que estas se estruturassem em termos de equipamentos relacionados aos setores de recebimento, estocagem e transformação de matérias primas, acelerando desta forma seu processo de crescimento econômico. 


\section{AS BASES IDEOLÓGICAS DO COOPERATIVISMO}

Embora incorporando particularidades e características de cada espaço geográfico em que é implantado, principalmente nos segmentos social e econômico, pode-se dizer que o cooperativismo é um sistema universal que se sustenta nos princípios da ajuda mútua e da ajuda própria, ou seja: é fundamentado em valores éticos em que o associado ajuda e ao mesmo tempo é ajudado pelos seus pares na obtenção de vantagens. Em sintonia com esses princípios, uma série de definições existe para caracterizar o que é cooperativismo. Segundo a ACI - Aliança Cooperativa Internacional, entidade que congrega as cooperativas no mundo inteiro, "cooperativa é toda a associação de pessoas que tenha por fim a melhoria econômica e social de seus membros, através da exploração de uma empresa sobre a base de ajuda mútua e que observe os princípios de Rochdale", destacados a seguir. Entre os autores brasileiros, destaca-se a definição de MACHADO (1975:17), segundo a qual a cooperativa "representa uma simbiose da ajuda mútua e da ajuda própria". Tais definições se completam com a seguinte explicação de SCHNEIDER (1981:32): “o cooperativismo surgiu, historicamente, como um sistema formal, porém simples, de organização de grupos sociais com objetivos e interesses comuns, estando o seu funcionamento amparado, basicamente, nos princípios da ajuda mútua e do controle democrático da organização pelos seus membros. Daí o caráter sui-gêneris desse tipo de organização, da qual os associados seriam, ao mesmo tempo, proprietários e usuários”.

O sistema cooperativista surgiu no contexto da consolidação do capitalismo e das consequências sociais e econômicas geradas pela Revolução Industrial na Europa, a partir da segunda metade do século XVIII, em função das propostas de Saint-Simon (1769-1825), de Charles Fourier (1772-1837), de Robert Owen (1771-1858) e de outros filósofos e pensadores da época. Embora diversas tentativas tivessem ocorrido antes, mas sem os resultados esperados, foi em 1844 que, pela primeira vez, uma cooperativa conseguiu colocar em prática todo um conjunto de teorias, com relativo sucesso. No dia 24 de outubro de 1844, um grupo de tecelões da localidade de Rochdale, Inglaterra, fundou a primeira cooperativa, dando a ela o nome de "Sociedade dos Probos Pioneiros de Rochdale". Com algumas adaptações introduzidas posteriormente, os princípios básicos da Sociedade passou a nortear os princípios do sistema cooperativista como um todo, sendo eles: 
- Liberdade de associação para aqueles que estejam dispostos a operar de boa fé, sem distinção de raça, cor ou credo.

- Direito a um voto assegurado a cada associado.

- Possibilidade de representação.

- Neutralidade política e religiosa.

- Distribuição de sobras líquidas aos associados, segundo a proporção do uso dos bens e serviços da sociedade.

- Operações a dinheiro e por preços justos.

- Atribuições de juros de capital, limitados, módicos.

- Reuniões frequentes dos associados para estudar a marcha da sociedade e seu desenvolvimento.

Nos congressos da Aliança Cooperativa Internacional - ACI, realizados em 1937 em Paris e em 1966 em Viena, os princípios de Rochdale foram reformulados, passando a apresentar-se da seguinte forma:

- Adesão livre - também conhecida como "princípio de porta aberta" e que possibilita o ingresso ou a saída do cooperado voluntariamente, sem coerção ou discriminação por motivos políticos, religiosos, étnicos ou sociais.

- Gestão democrática - ou administração dos próprios cooperados, através de delegados eleitos por tempo determinado, em assembléias gerais, nas quais cada associado tem direito a um voto apenas, sem nenhuma relação com sua participação no capital social.

- Distribuição das sobras líquidas: a) ao desenvolvimento da cooperativa; b) aos serviços comuns; c) aos associados prorata das operações que cada um realizou com a cooperativa.

- Taxa limitada de juros ao capital social ou pagamento de juros módicos ao capital, considerado este apenas como fator de produção.

- Constituição de um fundo para educação dos cooperados e do público em geral. 
- Ativa cooperação entre as cooperativas, em plano local, nacional e internacional.

Considerando tais princípios, RIOS (1987:15) afirma que "o cooperativismo é a base de um modelo de associação com as seguintes características: propriedade cooperativa; gestão cooperativa; repartição cooperativa", o que, respectivamente, significa: uma cooperativa é uma associação de pessoas e não de capitais; a assembléia de associados tem o poder último de decisão; as sobras financeiras, ao final do exercício fiscal, são divididas entre os associados.

Os princípios universais não engessam, entretanto, o sistema cooperativista. Flexibilizações são admitidas por conta das características de cada espaço geográfico onde é praticado, sendo esta, a propósito, uma condição para o crescimento e a consolidação das cooperativas. Segundo BIALOSKORSKI NETO (2000: 242), "a cooperativa só terá sucesso social, cumprindo com sua responsabilidade junto ao seu quadro associativo, se esta for um empreendimento econômico de sucesso de forma a permitir o crescimento (...) de seus associados". No Brasil, diante disso, as cooperativas vinculadas ao setor agrícola, passaram a crescer na exata proporção das vantagens financeiras que tiveram condições de oferecer aos associados, ficando relegados a segundo plano aspectos de cunho social e ideológico.

\footnotetext{
"Considerando seu distanciamento das bases ideológicas e sua consequente identificação com os valores econômicos e com a política dominante, as cooperativas brasileiras, de modo geral, foram estruturadas de cima para baixo, a partir de iniciativas governamentais e poucas vezes a partir de iniciativas das classes produtoras; se submeteram a um excessivo controle de órgãos governamentais, abrindo mão do direito de caminharem livremente; passaram a se preocupar muito mais em concorrer com empresas privadas capitalistas do que em prestar serviços a seus associados; passaram a se vincular muito mais com os modelos agrícolas voltados ao mercado externo do que com a produção de gêneros de consumo interno (SERRA, 1986:83).
}

Dentro de tal lógica de funcionamento, as cooperativas se transformaram em poderoso instrumento do Estado, por exemplo, no processo de implantação do novo modelo agrícola a partir dos anos 1960 mesmo que, em algumas situações, tal modelo não atendesse às aspirações do corpo associativo. 


\begin{abstract}
'Na região Norte do Paraná, onde o novo modelo só foi incorporado no final dos anos 1970, os agricultores, em grande parte filiados às cooperativas, eram tradicionais produtores de café, dependiam do trabalho familiar não remunerado e das lavouras de subsistência para se manter e só podiam contar com as pequenas dimensões de seu lote, situações que não se enquadravam nas características da nova fase da agricultura" (SERRA, 1986: 112).
\end{abstract}

Acrescenta ainda o mesmo autor:

\begin{abstract}
"O modelo tradicional era, ainda, grande absorvedor de mão-de-obra, o que fazia com que o homem se fixasse mais na zona rural do que na zona urbana, onde as possibilidades de inserção no mercado de trabalho eram mais restritas. O novo modelo, ao contrário, passou a depender muito mais de instrumentos que demandam capital do que do fator trabalho, o que gerou o desemprego no meio rural; passou a depender de áreas maiores para plantio, o que anulou o modelo de colonização implantado na região voltado às pequenas e médias propriedades $\mathrm{e}$ gerou a concentração fundiária; passou a implementar lavouras especializadas, o que anulou a diversificação de culturas com o conseqüente desaparecimento das lavouras de subsistência, levando junto toda a estrutura que existia nas propriedades em função das lavouras de café e da manutenção do homem no campo, incluindo casas, terreiros, tulhas, pomares, galinheiros, etc. (SERRA, 1986: 112)
\end{abstract}

Diante das transformações, as cooperativas regionais não assumiram qualquer posição em defesa dos produtores associados, principalmente dos pequenos, mergulhados em crise por não se adaptarem ao novo modelo. Embora todas tenham surgido em função do café, ficaram omissas quando o café e, junto, os cafeicultores, foram condenados ao desaparecimento na região. E sendo omissas, serviram aos interesses do Estado e passaram a cumprir importante papel na substituição das lavouras, em troca de subsídios que viabilizaram a construção de uma nova estrutura voltada ao recebimento, comercialização e industrialização dos novos produtos que passariam a receber, com destaque para a soja, o milho e o trigo. 
O novo modelo agrícola vai viabilizar o surgimento de um novo padrão de cooperativa no Brasil e, em particular, no Norte e no Oeste do Paraná: as cooperativasempresas. De maneira geral, até o surgimento do novo modelo, as cooperativas eram tradicionais recebedores e repassadores de matérias-primas produzidas pelos associados, cumprindo seu papel no rompimento da cadeia de intermediação. Nesta fase, colocavam-se bem próximas dos associados e se identificavam mais com as propostas e as teorias que deram origem ao sistema. Na nova fase, ao contrário, ao se consolidarem como grandes empresas híbridas acabaram se distanciando de suas bases sociais gerando, como conseqüência, uma série de ambigüidades que vão caracterizar sua nova forma atuação.

\section{A COCAMAR E SUA INSERÇÃO NO NOVO MODELO AGRÍCOLA}

Fundada em 1963 com a denominação de Cooperativa de Cafeicultores de Maringá, a COCAMAR teve sua origem associada à crise que atingia, na época, as lavouras cafeeiras provocada pela derrocada dos preços de mercado. $\mathrm{Na}$ ausência de outro mecanismo de comercialização, as safras tinham que ser entregues aos "maquinistas" ou a outros intermediários que, após o beneficiamento, exportavam o produto, se apropriando da maior parte da margem de lucros. Estando a comercialização centralizada nas máquinas de beneficiamento e em grandes empresas exportadoras, que manobravam o mercado segundo as tendências de cada momento e havendo uma sucessão de superproduções nas lavouras, o que passou a ocorrer foi o aviltamento dos preços pagos ao produtor a ponto da atividade cafeeira ser inviabilizada economicamente. O quadro vai levar o Estado, através do Banco do Brasil e do Instituto Brasileiro do Café, órgão extinto nos anos 1980, a orientar os produtores na fundação de cooperativas como instrumento de defesa diante dos momentos de dificuldades. As cooperativas fundadas com a orientação do BB e do IBC teriam que cumprir algumas funções que ajudariam a atenuar a crise, destacando-se: romper a cadeia de intermediação, colocando o produtor em contato com o consumidor ou, pelo menos, em contato com os grandes importadores, no mercado externo, o que viabilizaria a apropriação dos lucros desviados pelos intermediários; reter o produto excedente nas tulhas localizadas nas propriedades ou em armazéns da própria cooperativa, evitando que chegasse ao mercado onde poderia desequilibrar ainda mais a lei da oferta e da 
procura; orientar os produtores a diversificarem suas lavouras, tendo outras opções na agricultura, além do café.

Com a assessoria do BB e do IBC diversas cooperativas acabaram surgindo nas zonas cafeeiras paranaenses, todas no mesmo período - de 1960 a 1963 - e todas ostentando o título de cooperativa de cafeicultores, entre elas a COCAMAR. O vínculo com a cafeicultura vai, no entanto, perder sentido em meados dos anos 1970 quando fortes geadas atingem e destroem as lavouras regionais. Destruído o parque cafeeiro, então calculado na região Norte do Paraná em 915 milhões de covas, perdeu sentido lutar pela cafeicultura, o que leva as cooperativas de cafeicultores a repensar seu estilo de atuação. Na época, o Estado já vinha desenvolvendo uma política de desestímulo da cafeicultura no Paraná, de modo que a ocorrência de geadas viria facilitar a implantação de um novo modelo agrícola e o deslocamento do polo cafeeiro para outras regiões, com destaque para as antigas zonas produtoras de Minas Gerais.

No processo de substituição de lavouras, em que o espaço anteriormente ocupado pelo café vai ser liberado para as culturas mecanizadas, com destaque para a soja, o trigo e o milho, os trabalhadores e os pequenos proprietários pagam o preço mais alto. Os trabalhadores, porque perdem seus empregos no setor agrícola, diante de um quadro em que as novas lavouras passaram a depender muito mais do fator capital (tratores, colheitadeiras, por exemplo) e muito menos do fator trabalho, o que gera a dispensa em massa de empregados rurais; os pequenos proprietários, porque o novo modelo não se enquadrava na pequena extensão de suas propriedades, dependendo de áreas maiores, o que leva à concentração fundiária. Os impactos, diante da radical transformação, foram violentos no Norte do Paraná, justamente porque esta era a maior região produtora de café do País naquele período (anos 1960) e porque foi colonizada tendo como base fundiária os pequenos lotes e como base econômica de uso da terra as lavouras tradicionais de café, associadas com as lavouras de subsistência e com o trabalho familiar não remunerado, mecanismos que contribuíam para a fixação do homem na zona rural.

As cooperativas, a esta altura, não cumpriram nenhum papel no sentido de apoiar os associados mergulhados em crise. Foram, no entanto, sensíveis aos interesses do Estado, tanto que se transformaram em importante instrumento na consolidação das novas lavouras. No caso da COCAMAR, antes mesmo da entrada do novo modelo agrícola, a cooperativa já dispunha de um armazém para estocar produtos a granel, bem como toda a estrutura complementar, financiado a fundo perdido pelo Ministério da 
Agricultura, em 1972. Ou seja: pelo menos três anos das geadas, ocorridas em 1975, a COCAMAR já estava aparelhada para operar com novos produtos, ciente portanto de que o café estava com seus dias contados na região. $\mathrm{O}$ armazém foi o primeiro passo, sendo que outros equipamentos foram sendo implantados nos anos seguintes, em função das necessidades dos novos produtos agrícolas que passariam a ser cultivados pelos associados em lugar do café, da mesma forma com a ajuda oficial mediante uma política de créditos fartos e juros altamente subsidiados. Nesta nova fase, inaugurada nos anos 1970 e que vai ser consolidada depois das geadas de 1975, deixou de ter sentido o nome "Cooperativa de Cafeicultores": é aí que COCAMAR passa a significar Cooperativa de Cafeicultores e Agropecuaristas de Maringá e, posteriormente, Cooperativa Agroindustrial. Com as novas denominações, e em função da nova fase, deixa de trabalhar apenas com café e diversifica sua linha de recebimento de produtos agrícolas; deixa de ser apenas uma recebedora e repassadora de produtos entregues pelos associados, passando a também industrializar as matérias-primas que recebe.

\section{A C. VALE E A PRODUÇÃO INTEGRAdA}

Da mesma forma como a cooperativa da região Norte, a cooperativa da região Oeste do Paraná foi fundada em 1963, tendo como suportes a produção rural em crise e o decisivo papel do Estado na organização dos produtores visualizando o sistema associativista como alternativa mais viável para, se não resolver, pelo menos atenuar o nível de dificuldades enfrentadas. A diferença que vai marcar a origem das duas cooperativas é que enquanto a COCAMAR esteve atrelada às dificuldades dos pequenos produtores de café, a C. VALE (o nome original era CAMPAL - Cooperativa Agrícola Mista de Palotina) teve como proposta inicial socorrer pequenos produtores atrelados, nos anos 1960, a uma agricultura bastante diversificada, considerada por BELUSSO (2007:39) como "policultura de subsistência".

No que se refere às características que vão marcar o perfil dos primeiros associados, a COCAMAR vai atuar inicialmente com produtores rurais que se deslocaram de São Paulo a partir dos anos 1920 para produzir café no Norte do Paraná, atraídos pelas terras férteis dessa região e que se adaptavam a tal produto agrícola de mercado e pelas condições facilitadas com que essas terras podiam ser adquiridas das empresas colonizadoras. A C. VALE, por sua vez, vai atuar no contexto de um quadro social constituído em sua maior parte por colonos gaúchos e catarinenses que se 
deslocaram para o Oeste e Sudoeste do Paraná a partir dos anos 1940, trocando minifúndios antieconômicos em seus estados de origem por espaços maiores que podiam ser adquiridos nas últimas frentes colonizadoras do Paraná, da mesma forma como na região Norte, em condições facilitadas, à altura das condições econômicas dos pequenos agricultores.

\footnotetext{
"Os desmembramentos sucessivos das colônias nas regiões coloniais no Rio Grande do Sul e de Santa Catarina é que ocasionaram o surgimento dos minifúndios que estavam inviabilizando a reprodução social do colono. Desta forma, o movimento migratório para o sudoeste e oeste paranaenses era uma das alternativas apresentadas" (YOKOO, 2002:135)
}

Os estatutos sociais da cooperativa sediada no município de Palotina, região Oeste, definem com clareza os objetivos dos pequenos agricultores que participaram, em 1963, da assembléia de fundação:

\footnotetext{
"Proporcionar aos associados a defesa de seus interesses econômicos, promovendo a venda em comum de sua produção agrícola ou pecuária, visando sempre a obtenção de melhores preços e adquirindo para os mesmos tudo o que necessitarem para suas culturas ou criações, ou ainda artigos de uso pessoal e doméstico, sempre procurando melhor preço e melhor qualidade" (BELUSSO, 2007:50)
}

No plano prático, "em 1963, ano de sua fundação, o objetivo que motivou a cooperativa era um armazém e um caminhão" (BELUSSO, 2007:50), acreditando que o meio de transporte e o armazenamento da produção ajudariam a romper a condição de dependência que mantinham com os atravessadores intermediários. O interesse do setor público, entretanto, era outro: "O apoio dos governos federal e estadual incentivava a criação de cooperativas como meio de viabilizar a substituição da agricultura colonial pelo binômio soja e trigo" (BELUSSO, 2007:42). Tanto que dois anos depois, em 1965, os agricultores eram persuadidos a utilizarem os recursos do recém-criado Sistema Nacional de Crédito Rural (SNCR) para mudarem a estrutura de suas propriedades e trocarem as lavouras de subsistência pelas lavouras mecanizadas. 
Os recursos do SNCR, aplicados na agricultura, contribuíram para uma rápida mudança tanto no horizonte da área de atuação da cooperativa, como na própria cooperativa, igualmente beneficiada com os créditos altamente subsidiados. Desta forma, empresa e propriedades dos associados passam por uma fase de profundas transformações em sua base técnica, ela ingressando na fase de industrialização, eles mudando radicalmente sua forma de produção, seguindo a lógica do novo modelo agrícola. A política de financiamentos viabilizada no País pelo SNCR teve numa ponta o produtor rural como beneficiário e em outra as entidades ou empresas que os representava, numa espécie de prolongamento urbano do rural, no caso as cooperativas. “Assim, o processo de modernização da agricultura no Brasil altera diretamente o perfil das cooperativas. Se até o início da década de 70, estas apresentavam uma estrutura tipicamente comercial, após esse período passam a integrar o CAI" (COSTA, 1992:12).

$\mathrm{Na}$ nova fase, a cooperativa do Oeste ingressa em estágio desenvolvimentista que se marca pela ampliação de sua área de atuação, que tem como resultado a elevação do número de associados e da produção agrícola entregue, e pela implantação de indústrias. A ampliação da área se dá pela incorporação de cooperativas de Mato Grosso (Cooperativa Agrícola Mista de Diamantino, instalada no município do mesmo nome) e de Santa Catarina (Cooperativa Agrícola Mista Regional Pindorama, que atuava nos municípios de Abelardo Luz e Faxinal dos Guedes). A industrialização se dá de forma modesta nos anos 1980, quando implanta uma fábrica de ração e uma usina de descaroçamento de algodão, e de forma mais arrojada na década seguinte quando implanta o que denomina de Complexo Industrial Avícola C. Vale, composto por matrizeiro (produção de ovos), incubatório (produção de pintainhos), abatedouro de aves e nova fábrica de ração. No campo, para viabilizar tal estrutura industrial em termos de matéria prima, passou a incrementar a instalação de aviários convencionais e climatizados, estes incorporando maior tecnologia do que aqueles na produção de frangos para abate, em menor tempo e com maior qualidade.

As fases de crescimento e de inovações na forma e na estrutura de atuação foram acompanhadas por mudanças na designação da cooperativa. Assim, nos anos 1960 a denominação inicial, que era Campal - Cooperativa Agrícola Mista de Palotina passou nos anos 1980 para Coopervale - Cooperativa Agrícola Mista Vale do Piquiri e nos anos 1990 para a denominação que conserva até o momento: C. Vale - Cooperativa Agroindustrial. A principal modificação, no entanto, ficou por conta do quadro associativo, onde passaram a conviver associados livres (os que produzem e entregam 
produtos agrícolas) e associados integrados (os vinculados ao setor avícola), presos a rígido contrato de subordinação com a empresa. "Tal contrato estabelece uma série de exigências para que o avicultor efetue o crescimento dos frangos, sendo que, não o fazendo por ato de sua responsabilidade, responderá civil e criminalmente, nos termos da lei” (BELUSSO 2007:70). Na relação mútua com a nova categoria de associados, a cooperativa repassa os pintainhos, todos os insumos necessários, incluindo ração e medicamentos e presta toda a assistência técnica necessária; na contrapartida, os produtores assumem a responsabilidade pela engorda das aves dentro dos padrões de qualidade exigidos pela empresa, o que implica na prestação de trabalhos e em assumir despesas com o pagamento de funcionários, encargos trabalhistas e gastos em energia elétrica, gás, água e outros que forem necessários à atividade. $\mathrm{O}$ espaço onde se dá a produção, incluindo os aviários, pertence ao produtor, que dedica ainda todo o seu trabalho e arca com os custos; a produção, no entanto, não é dele, mas da cooperativa, que repassa os pintainhos e recebe em troca frangos prontos para o abate. A remuneração do "trabalho prestado" se dá em função do Índice de Eficiência Produtiva (IEP), que considera nos seus cálculos fatores como taxa de mortalidade, ganho de peso diário e conversão alimentar (ração/carne).

Em função dos produtores integrados é que a cooperativa de Palotina assumiu a face híbrida e ao mesmo tempo contraditória do cooperativismo. "Os produtores integrados formam a classe contraditória do grupo de associados, ou seja, o associado não seria passivo de um contrato porque se entende que este contraria a relação de fidelidade entre a cooperativa e os demais associados, pois fere o princípio de liberdade do cooperativismo" (BELUSSO, 2002:68).

\section{A INDUSTRALIZAÇÃO E A INSERÇÃO NO CAI}

A passagem, de uma cooperativa que recebia e comercializava matérias-primas, para uma cooperativa que recebe matérias-primas e as transforma em produtos industrializados para chegar diretamente ao mercado consumidor, só foi possível graças à estruturação de um parque industrial bastante sofisticado que envolve unidades de beneficiamento e transformação de grãos (soja, caroço de algodão, girassol, café), de fios (algodão, seda), de frutas (laranja) e de outras matérias primas, produzidas ou não pelos associados, no caso da COCAMAR e graças ao complexo avícola, no caso da $\mathrm{C}$. VALE. Na medida em que o parque industrial foi sendo estruturado e diante do risco de 
não ter matérias-primas em suficiência para manter as unidades de transformação em funcionamento constante, a cooperativa da região Norte passou a trabalhar com terceiros e também com produtores integrados, comportamento que, se de um lado lhe garantiu o suprimento de matérias-primas, de outro lado contribuiu para minimizar a importância do associado perante sua estrutura de funcionamento.

Ao operar com associados, terceiros e integrados, as cooperativas transformamse em empresas híbridas, cuja evolução independe de quesitos como representatividade e fidelidade do quadro associativo. Paralelamente, comportam-se como organizações que, no âmbito da restrita atuação junto aos associados, podem não assumir o lucro como meta, vestindo desta forma a camisa ideológica do sistema cooperativista, onde, no lugar do "lucro", "sobra" constitui o termo mais adequado; mudando-se para os outros segmentos que atende, no entanto, o lucro passa a ser vital para a atividade econômica que desempenham. O caráter híbrido e ao mesmo tempo contraditório que vai marcar a atuação das duas cooperativas se prende ao sentido de manter, ao mesmo tempo, relação paralela entre uma categoria de produtores "livres" e uma categoria de produtores "integrados". São "livres" os produtores associados à cooperativa que mantêm, por exemplo, uma relação de compra de insumos e venda da produção agrícola, obedecendo a certos princípios de mútua fidelidade. São "integrados" os produtores, também associados à cooperativa, porém compromissados por meio de contratos de parceria para a produção de determinada matéria prima industrial, observando-se que tal forma de "prender" o associado a cláusulas contratuais fere o princípio de liberdade do cooperativismo. No Paraná, o exemplo mais comum de integração produtor/cooperativa se dá no setor avícola voltado à produção de aves para abate, onde a C. VALE tem intensa atuação.

É diante do novo quadro, consequente de seu processo evolutivo, que a COCAMAR e a C. VALE assumem seu papel contraditório perante as normas do sistema cooperativista, passando a conviver, ora com a ideologia de sua formação, ora com a prática de sua sustentação econômica. E é no contexto desse quadro contraditório que os associados, num dado momento podem ser classificados como "donos" do empreendimento, mas que, logo em seguida, perdem força para um "talvez" carregado de dúvidas e de indefinições.

A inserção da cooperativa na fase da industrialização vai garantir como consequência direta, sua inserção no Complexo Agroindustrial, graças aos setores ligados à indústria de transformação de matérias primas agrícolas, ou agroindústrias, 
que instala a jusante do CAI. Os novos setores viabilizam o crescimento econômico da cooperativa, sua consolidação como empresa capitalista de grande porte, mas, contraditoriamente, esse crescimento, pelo menos em parte, ocorre à margem ou independente do corpo associativo. Isso não significa que os associados ficaram parados no tempo e no espaço, apenas assistindo a evolução da cooperativa da qual fazem parte; mas significa que não ocorreu uma relação direta entre o crescimento de um e a participação do outro.

Em toda a sua história, em nenhum momento a COCAMAR e a C. VALE distribuíram prejuízos ou captaram recursos diretamente entre os associados para custear, por exemplo, algum investimento. Existiram diversas situações em que elas deixaram de repassar dividendos, na forma de rateios, mas nenhuma indicando captação direta de recursos. Isso significa que a consolidação do parque industrial e das próprias cooperativas como empresa não dependeu da expropriação direta dos produtores associados, tendo relação maior com benefícios carreados pelo Estado através de financiamentos subsidiados e com o grau de eficiência da diretoria na condução de uma política de investimentos. Os incentivos oficiais que beneficiaram a COCAMAR e a C. VALE principalmente durante os anos 1970, são resultantes da política de crédito vinculada ao Sistema Nacional de Crédito Rural, mecanismo que sustentou a modernização da agricultura brasileira a partir de 1965.

\footnotetext{
"A modernização da agricultura brasileira teve o seu maior crescimento e intensificação com a estruturação do Sistema Nacional de Crédito Rural (SNCR), em 1965. Na década seguinte, os financiamentos fluíram com uma enorme facilidade, permitindo que os produtores e agroindústrias pudessem se capitalizar e se integrar" (BELIK; PAULILO, 2001:95)
}

A contribuição dos associados se deu com a retenção das sobras não distribuídas pela cooperativa no final de exercícios fiscais e transformadas em investimento a partir de decisões coletivas tomadas em assembléias gerais.

Por outro lado, a utilização do parque industrial, adquirido em nome dos associados, para a transformação de matérias-primas entregues por terceiros (agricultores não associados), bem como sua locação para outras empresas, em momentos de ociosidade das máquinas, são situações que geram agregações de valores 
em benefício apenas da cooperativa, mas não de seus associados, considerando que não foi deles ou não saiu de suas propriedades a mercadoria transformada. Ora, não havendo a expropriação direta e também não havendo a utilização exclusiva dos equipamentos em função dos produtores filiados ou de suas mercadorias agrícolas, em parte deixa de haver a esperada sintonia entre o desempenho da cooperativa e o repasse de seus benefícios, na forma monetária, para o corpo associativo, embora, pelo menos teoricamente, esses sejam os verdadeiros donos da empresa.

No caso da COCAMAR, essa relação híbrida, produto de uma conjuntura em que o crescimento da cooperativa ocorreu e ainda ocorre não totalmente dependente da participação direta dos associados, ganha importância histórica no primeiro e no segundo anos do século XXI, quando o setor industrial, atrelado ao setor comercial atacadista e varejista, passa a responder pela maior fatia do faturamento geral da empresa e quando boa parte desse setor não está diretamente relacionada à produção agrícola do quadro associativo, nem mesmo do setor agrícola regional. A COCAMAR ingressa no setor de sucos concentrados, de maionese, ketchup, transformando em industrializados produtos que não são próprios da agricultura de sua área de atuação, e como conseqüência não saem das lavouras dos associados: ela os recebe de outras indústrias, na forma de semi-manufaturados, completa o processo de industrialização, envasa e lança no mercado com sua marca. Nesta fase de seu processo evolutivo, a empresa encontra justificativas para mudar, pela terceira vez, sua denominação. COCAMAR, que começou como Cooperativa de Cafeicultores de Maringá, que mudou para Cooperativa de Cafeicultores e Agropecuaristas de Maringá, agora é batizada como Cooperativa Agroindustrial.

O crescimento, mais que crescimento, a metamorfose das cooperativas, gera contradições e novas ambigüidades em relação à filosofia e às próprias bases do cooperativismo. Não há como negar, por exemplo, que o quadro associativo perdeu sua importância na sustentação das empresas, sofrendo, em relação a elas, o que seria pelo menos na aparência, uma ruptura social e econômica. O distanciamento, que coloca a cooperativa de um lado e o corpo associativo do outro, vai encontrar sustentação diante do seguinte quadro:

- Teoricamente, passou a existir "uma" cooperativa vinculada ao corpo associativo e "outra" independente dele, mas funcionando com o mesmo nome e no mesmo endereço; uma 
que presta contas de suas atividades e outra que dispensa tal papel.

- Como o patrimônio da cooperativa pelo menos em parte cresceu independentemente da participação direta dos associados, deixou de existir o poder de decisão da assembléia geral em torno de "qualquer" assunto, continuando a existir apenas em relação a "alguns" assuntos, estes relacionados à cooperativa vinculada ao corpo associativo.

- No caso da distribuição de sobras, estas acabam sendo separadas, considerando que uma parte foi gerada com a participação dos associados e outra foi gerada em função de outras atividades desenvolvidas pela empresa, sem a participação direta do quadro social.

- As sobras não distribuídas e não contabilizadas na conta capital dos associados, não podem, da mesma forma, ser apropriadas por qualquer outro segmento social: a diretoria, por exemplo. O destino é serem transformadas em novos investimentos que vão acelerar o crescimento da empresa e, contraditoriamente, o seu distanciamento das bases sociais.

Considerando tais situações, que são concretas, pode-se chegar a uma, que não é concreta: diante de uma hipotética liquidação da empresa, os associados têm direito, de acordo com as normas cooperativistas, a receber o correspondente ao volume depositado em sua conta capital, com as devidas correções. Ocorre que no caso da COCAMAR e da C. VALE o patrimônio liquido é muitas vezes superior ao montante da conta capital, considerando que foi constituído em grande parte graças a um conjunto de atividades que não dependeu do esforço do quadro social. A ajuda do Estado através da liberação de créditos subsidiados, a operação com terceiros (agricultores não filiados), a eficiência do sistema administrativo, a agregação de valores capitalizados e convertidos em máquinas e equipamentos, que vão explicar e justificar o patrimônio adicional da cooperativa, não podem ser desconsiderados na eventualidade de um ajuste final de contas. 
A questão que surge: a quem seria destinada a parcela do crescimento extraordinário? A resposta não é encontrada nas normas que regulamentam o sistema cooperativista.

\section{REFERÊNCIAS}

BELIK, W. e PAULILO, L. F. O financiamento da produção agrícola brasileira na década de 90: ajustamento e seletividade. In: LEITE, S. P. (org.). Políticas públicas e agricultura no Brasil. Porto Alegre: Editora da UFRGS, 2001. pp.95120.

BELUSSO, Diane. A Cooperativa C. Vale e as perspectivas dos produtores integrados à agroindústria em Palotina-PR. Maringá, UEM, 2002 (Dissertação de Mestrado).

BIALOSKORSKI NETO, S. Agribusiness Cooperativo. In: ZYLBERSZTAJN, D. e FAVAN, M (orgs.). Economia e gestão dos negócios agroalimentares: indústria de alimentos, indústria de insumos, produção agropecuária, distribuição. São Paulo: Pioneira, 2000, pp. 235-251.

BORDA, Orlando Fals. Formación y deformación de la política cooperativa en América Latina. Boletin do Instituto Internacional de Estúdios Laborales. Genebra, (7):135-65, 1970.

COCAMAR, Cooperativa Agroindustrial. Relatório 2004.

COOPERATIVA AGROINDUSTRIAL. COCAMAR: uma história em quatro décadas. Maringá, 2003 (edição comemorativa).

COSTA, Vera M. H. de Miranda. A modernização da agricultura no contexto da constituição do Complexo Agroindustrial no Brasil. Anais: XI Encontro Nacional de Geografia Agrária. Maringá, 1992, pp. 02-27. 
MACHADO, P. Antonio. Comentários à Lei do Cooperativismo. São Paulo: Unidas, 1975.

RIOS, G. S. L. O que é cooperativismo. São Paulo: Brasiliense, 1987.

SCHNEIDER, J. Elmo. O cooperativismo agrícola na dinâmica social do desenvolvimento periférico dependente: o caso brasileiro. In: LOUREIRO, M. Rita, org. Cooperativas Agrícolas e Capitalismo no Brasil. São Paulo: Cortez, 1981.

SERRA, Elpídio. Contribuição ao estudo do cooperativismo na agricultura do Paraná: o caso da Cooperativa de Cafeicultores e Agropecuaristas de Maringá. Rio Claro: UNESP, 1986 (Dissertação de Mestrado).

YOKOO, E. Noriyuki. Terra de negócio - estudo da colonização no oeste paranaense. Maringá: UEM, 2002 (Dissertação de Mestrado). 